\title{
Situated Learning and the Management of Learning: A Case Study
}

\author{
Karen Barton \\ Dept of Business Information, Glasgow Caledonian University \\ Patricia McKellar \\ Dept of Law and Public Administration, Glasgow Caledonian University \\ Paul Maharg \\ Law School, University of Strathclyde
}

\begin{abstract}
Situated learning, focusing on the pragmatic and social aspects of learning, has as its basis the notion that learning is essentially dependent on the immediate situation of action. It is a strength of the theory that it supports learner-centred instructional design (ID), and supports a constructivist approach to ID.

Nevertheless, even a learner-centred theory such as situated learning requires more if its product is to be successful in facilitating learning. Student learning requires management at every level: within individual learning activities, within a module syllabus and within a curriculum. The contextual issues which go to make up such management, and the relations between situated learning theory and learning management, are the focus of this paper. We shall argue that it is essential for the success of embedded IT that instructional designers pay attention to learning management issues, that they signal the presence of these issues in their courseware documentation, and that lecturers and tutors who use the courseware should take these issues into account when implementing and embedding computer-based learning in the curriculum.

As an example of this argument we take our computer-based learning program the Virtual Court Action. This program was designed to be used in the learning and teaching of procedural law in a Scottish university law curriculum. Using document assembly techniques and email, this program emulates part of a civil court action in a Scottish court, with identical personnel, legal documents and procedure. The place of situated learning theory in its design is described, and the learning management issues germane to its implementation are analysed. Finally, we show how the attention paid to learning management issues contributed to the success of the program.
\end{abstract}

'Acting on the world to learn about concepts is not a straightforward issue.'

'Old-fashioned pocket knives ... have a device for removing stones from horses' hooves. People with this device may know its use and be able to talk wisely about horses, hooves and stones. But they may never betray -- or even recognise -- that they would not begin to know how to use this implement on a horse. ${ }^{2}$

\footnotetext{
${ }^{1}$ Laurillard, D. (1993) Rethinking University Teaching: A Framework for the Effective Use of Educational Technology, Routledge, London, p.61

2 Brown, J.S., Collins, A. and Duguid, P. (1989) 'Situated Cognition and the Culture of Learning',

Educational Researcher, 18, 1, 32-42 , p.33
} 


\section{Introduction $^{3}$}

The general development of theory within a disciplinary domain is rarely if ever a methodical and well-planned venture. Disciplines are formed in part by the logic of discovery, encounter, accommodation, qualification, and are rooted in historical contingency. This is as true of the history of the theory surrounding educational technology as it is of education or of law itself, or indeed any other discipline in the academy. Inevitably, this process leads to imbalances and gaps: some areas of the domain may become extensively theorised, while others may remain relatively neglected. Within computer-assisted legal education one such neglected area is that of 'learning management'. While there are a number of related treatments of this theme, the term 'learning management' was probably first used as a term of art by Stephen Draper in a recent ITFORUM discussion paper ${ }^{4}$. By the term, Draper refers to the 'control or management or administration' of activities which allow learning to take place:

Many CAL applications have foundered because the package is delivered and applied with ONLY 'learning' ie conceptual issues addressed. All the 'management' issues about when to use it, how much to expect to do at a time, where to get help, how it will be assessed, how to turn the computer on, how to get into the package, etc. etc. etc. are almost always omitted, and often teachers do not grasp this until they have a large disaster on their hands.

Learning management, in our experience, is critical to the success of any CBL intervention. In this paper, therefore, we shall describe a C\&IT project in document assembly, the Virtual Court Action, in which learning management played a key role in the project's success. We shall then illustrate the theoretical bases underlying the project and highlight the importance of learning management in the operationalising of these theories. ${ }^{5}$

\section{Case Study : The Virtual Court Action}

The Virtual Court Action was developed at Glasgow Caledonian University, and designed to be delivered in a specific module. Right from the start therefore we were aware of and able to take into account local issues of learning management. The project was designed to teach students court procedure by allowing them to become the pursuers and defenders in their own hypothetical court action, using technology to simulate the real life environment. The constraints of academic curricula do not allow students to

\footnotetext{
${ }^{3}$ This paper is the result of conversations and discussions with people as much as with IT and learning theory and practice. Our thanks to Max Young for a discussion at the Stockholm SubTech Conference of issues surrounding student access; and to Abdul Paliwala for ongoing discussions about the relationship of theory and practice in C\&IT.

${ }^{4}$ Draper, Stephen, (11 April 1997), 'Adding (negotiated) learning management to models of teaching and learning' at http://itech1.coe.uga.edu/itforum/paper21/paper21.html. (13 September 1998)

${ }^{5}$ In this paper we have, for convenience' sake, adopted the acronym CBL (computer-assisted learning) to stand broadly for forms of learning in which computers are used significantly to enhance learning. We also use the acronym C\&IT (Communications and Information Technology), because the project was built around the concept of communications between role-playing students.
} 
learn procedural law in the real environment of the court where opportunities to become actively involved in tasks are present. As a result, even with the inclusion of case law, and with examples to contextualize the procedural principles, the subject can be perceived as an exercise in knowledge acquisition alone. ${ }^{6}$

We therefore set out to develop a method of teaching court procedure which could integrate theory and practice in context, and which we hoped would promote a deeper understanding of the subject and reduce students' dependence on rote learning. ${ }^{7} \mathrm{We}$ knew of document assembly techniques from our experience of earlier CBL and our interest in rhetoric, and we made the decision to use HotDocs, an intelligent document assembly application which interfaces with a number of standard word processing programs. This software provided an environment in which we could design and author complex templates from which final documents could be produced by the students. ${ }^{8}$ By using authentic learning tasks and encouraging learning through discovery rather than instruction we hoped to enable students to construct their own understanding of court procedure, as well as to acquire the acquisition of relevant transferable skills. In the development of the project, we were careful to avoid an instructional design where the emphasis was on drill and practice. Rather we aimed to create a student-centred, problem-solving environment where students would become active participants in the learning process. Integration of legal theory and practice would, we hoped, also result in improved quality of learning. ${ }^{9}$

\section{Development of the Project}

The aim of The Virtual Court Action was to develop students' understanding of the progression of an ordinary civil court action along with the interactions that take place between the various parties and to develop students' understanding of the content of the legal documents which form the basis of the action. The project was piloted over a four week period in February 1997 with 70 full-time and part-time undergraduates. ${ }^{10}$ The students were assigned to groups of three, and each group became the pursuer or defender in a civil court action. The role of the Sheriff Clerk was taken by the course tutor. Each side was issued with a unique case scenario which gave sufficient information to allow them to initiate or defend the action. The students then actively progressed the action to an identifiable point in the procedure by drafting the appropriate legal documentation and corresponding with each other and with the Sheriff Clerk using email. The project was not designed to stand alone, or to replace traditional learning methods, but the number of weekly seminars was reduced for the duration of the project.

\footnotetext{
${ }^{6}$ For an exploration of these issues, see Vaughn, R.G. (1995), 'Use of simulations in a first-year civil procedure class', Journal of Legal Education, 45, 480-86

7 The importance of such integration has been described by a number of educationalists. See for example Eraut, M. (1994) Developing Professional Knowledge and Competence, Falmer Press, Lewes

${ }^{8}$ It was only later that we learned of the outstanding work of Larry Farmer with HotDocs, a knowledge that enriched our understanding of the context of document assembly.

${ }^{9}$ Barton, K., McKellar, P. \& Maharg, P. (1998) 'Learning from Learning: The Dialogue of Virtual and Real Courts', 13th BILETA Conference, Dublin, Ireland

${ }^{10}$ K. Barton \& P. McKellar, (1998), 'The Virtual Court Action: Procedural Facilitation in Law', Association of Learning Technology Journal, 6, 1, 87-94
} 
In order for the project to work effectively we had to devise a process whereby students could create documents with ease. This problem was tackled by identifying text variables within template documents, and linking these variables to user prompts and help text. We then created and customised a user interface by grouping variables into dialogues, providing help text where appropriate.

Dialogue types were employed in each document template in order to provide a rich and appropriate learning environment. The dialogues asked students to carry out a number of tasks, ranging from simple selection out of a list of given options to drafting sections of text incorporating legal argument. In the process, it was crucial for us to see tasks from the students' point of view, and to distinguish between cognitively simple and cognitively complex tasks. A number of simple tasks could be completed by the software to allow students time to concentrate at critical points on the complex tasks where they would require to consider document format, content, audience, procedural alternatives, timelines, or any combination of these. The level of task complexity was carefully planned to take account of the increase in the cognitive complexity, which became greater as the presence of the above factors increased. These tasks ranged from, for example, selecting the grounds of jurisdiction from a given list, to drafting pleadings and legal argument.

In addition when designing dialogues and user interfaces we sought to reflect the thought process of the writer in drafting the document rather than following the strict physical layout of the document. Based on approaches derived from rhetorical literature, and in particular suggested by Scardamalia and Hewitt, the software was used as the means for 'off-loading... to reduce unwanted complexity ...' and thus '... it allows people to better focus on higher cognitive demands'. ${ }^{11}$ The dialogues and interfaces therefore did not always follow the set format of the document but were designed to facilitate for students the problem solving environment.

In order to assist students in drafting documents we designed help text at key points in the dialogues to provide a support scaffold for students' decisions. We hoped this scaffold would alert students to the necessity to make a decision, without telling them which decision it was, or the appropriate solution. In this we were aware of the tension between 'explicit knowledge and implicit understanding' in the cognitive coaching we were developing. More particularly, the scaffold allowed us a space in which to define terms, direct students to legislation, explain aspects of procedure, guide students' strategic choices and alert students as to the consequences of specific decisions.

Students carried out the legal action by accessing a library of document templates

\footnotetext{
${ }^{11}$ Scardamalia, M. and Bereiter, C. (1986) 'From Conversation to Composition: the Role of Instruction in a Developmental Process', in Glaser, R., editor, Advances in Instructional Psychology, vol 2, Lawrence Erlbaum Associates: Hillsdale NJ. For further exploration of the ways in which rhetorical strategies are important in the construction of legal learning via C\&IT, see Maharg, P., 'Contracts: An Introduction to the Skills of Legal Writing and Analysis', Journal of Information, Law and Technology, vol 1, part 1, 31 January 1996, http://elj.warwick.ac.uk/jilt/cal/1maharg/default.htm; and Maharg, P. (2000) 'Law, Learning, Technology: Reiving Ower the Borders', International Review of Law, Computers \& Technology, forthcoming.
} 
available to all parties. Each group then required to identify the appropriate document for their roles as either pursuer or defender at the particular stage in the action. They needed to assemble the document by answering questions presented in the dialogues. During this process students responded to various dialogues and prompts presented to them. These responses were merged with the template to produce the final formatted document. The resulting document was then sent to the appropriate party by email. The action continued as in the real court environment with the parties responding to documentation received, assembling documents for their client, and corresponding with each other and the Sheriff Clerk. Time limits were based on those set by the Court, taking account of Caledonian university's semester system.

An example of a template dialogue is reproduced in figure 1, below:

In ordinary actions you will have to establish jurisdiction in the particular sheriff court where the action is to be raised.

You must carry out the following tasks in this section:

TASK 1] Select the grounds of jurisdiction.

TASK 2] Select the sheriffdom.

TASK 3] Type the sheriff court district.

Click HELP for an explanation of each of the main grounds of jurisdiction.

Finish

HERE IS THE FIRST TASK. SCROLL DOWN FOR THE OTHER TASKS.

Cancel

Help

Clear

TASK 1] Select the grounds of jurisdiction :

O Domicile-Individual

Domicile - Corporations, Associations

Special Jurisdiction

Consumer Contracts

Exclusive Jurisdiction

Prorogation of Jurisdiction 


\section{Figure 1}

This is a screen shot of a dialogue from the routines designed to assist students to draft an initial writ. The dialogue question sets 1-3, two of which are shown above, lead students through the stages of drafting the writ. To complete the writ, students require to compare the details in their scenarios with the dialogue questions. In addition, we provided Help texts for crucial terms and processes. Thus the Help text on Domicile (in figure 2 below) defines key terms and processes for students, and reinforces the topics taught in lectures

and tutorials:

In ordinary actions you will have to establish jurisdiction in the particular sheriff court where the action is to be raised.

\section{Next}

Previous

You must carry out the following tasks in this section:

TASK 1] Select the grounds of jurisdiction.

TASK 2] Select the sheriffdom.

TASK 3] Type the sheriff court district.

Click HELP for an explanation of each of the main grounds of jurisdiction.

HERE IS THE FIRST TASK. SCROLL DOWN FOR THE OTHER TASKS.

[TASK 1] Select the grounds of jurisdiction :

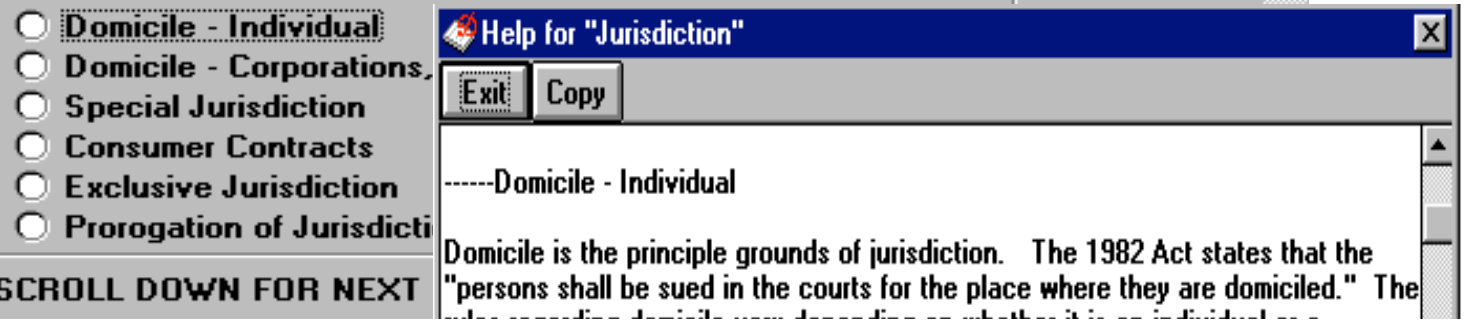




\section{Figure 2}

From similar computer-mediated communications projects carried out in the department we were aware that there could be problems of training in, and access to, email on the Faculty networks. The students received a one hour training session prior to the commencement of the project, and -- bearing in mind the learning management of the project from a student perspective -- were provided with user guides for the Virtual Court Action and email. Student feedback from questionnaires showed that this was adequate preparation (for example, over 90 per cent said the dialogues were straightforward to complete). Students used network drop-in time to complete the project but, aware of the difficulties inherent in drop-in time outlined above, we timetabled one unsupervised hour on a network per week.

At the conclusion of the project, the students were required to submit for assessment, inter alia,

- a group portfolio which included a printed copy of all documentation pertaining to their case;

- an individual report which identified and summarised the learning objectives and skills that had been met as a result of participating in the project

\section{Co-operative Learning}

Based on our own evaluation of the pilot project, we considered ways to increase opportunities for co-operative learning. Once again, the way forward here arose from reflection upon the learning management issues that presented themselves. It became clear during the pilot project that several common issues were being raised with the tutor by the student groups. This was an ineffective use of staff time. To reduce the need for tutor support, and encourage co-operative learning, we considered introducing a peer discussion forum.

There are two main reasons why we thought this might help us manage and facilitate student learning. First, dialogue with peers and tutors has been a fundamental premise of higher education and is an important element of deep learning and reflective thought. 
Traditionally this dialogue has taken place only when participants have been physically present, but technology now provides forums for discussion which do not rely on face-toface communications. Compilations of these electronic dialogues for use as an educational delivery method have been referred to as 'tertiary courseware'. ${ }^{12}$ An example of this has been developed by Ackerman and Malone with the implementation of the 'Answer Garden'. ${ }^{13}$ This is a system which allows databases of frequently asked questions of shared interest groups to be developed. As new questions are answered, by 'experts', they are then added to the growing database. ${ }^{14}$ Secondly, electronic dialogues can have the additional benefit of simulating the real professional legal environment where colleagues would engage in regular dialogue. Accordingly, we set up a HyperNews discussion group located on the MAN Project, the Clyde Virtual University. ${ }^{15}$ The discussions evolve as hierarchical structures with icons attached to contributions indicating, for example, questions, feedback, agreement or new ideas.

Students were invited to enter the discussion group when they had procedural, legal or software issues regarding the project and which could not be resolved within their own pursuer/defender group. They were also encouraged to visit the site and contribute to discussions and debates raised by other participants. Discussions 'grew' in a similar way to the 'Answer Garden' with the tutor taking the role of the 'expert' entering the forum to direct and facilitate debate when necessary.

We were aware that students may have been reluctant to enter such a novel forum and in order to encourage participation students were given training on the use of HyperNews. In addition, they were obliged to enter the discussion at least once during the course of the project and their contribution formed part of their overall assessment. The Virtual Court Action incorporating a HyperNews discussion forum was completed by 80 undergraduates in March 1998.

\section{Student Feedback}

Formative evaluation was employed during development of the templates and user interfaces in order to determine the ease of navigation within and between templates. This took the form of videotaped talk-aloud protocols which were used with groups of students. After studying their responses and comments, a number of aspects of the user interface were modified. In the summative evaluation students were asked to provide feedback in the form of a questionnaire as well as in the report which was submitted for

\footnotetext{
${ }^{12}$ Mayes, J.T. (1995), 'Learning Technology and Groundhog Day', in Strang, W., Simpson, V. \& Slater, D. (eds) Hypermedia at Work: Practice and Theory in Higher Education, University of Kent Press, Canterbury

${ }^{13}$ Ackerman, M., Malone, T. (1990), 'Answer garden: a tool for growing organisational memory', Proceedings of the Conference on Office Information Systems, ACM Press, New York

${ }^{14}$ Beach and Lundell describe the interpretive aspect of discussion forums. Talking of computer-mediated communications, they observe that it "creates an electronic forum or "interpretative zone" in which participants share multiple perspectives and attitudes relative to a particular topic or issue' (Beach, R. \& Lundell, D. (1996) 'Early adolescents' use of computer-mediated communication in writing and reading', paper presented at the HRRC conference on computers and literacy, Decatur, Georgia, quoted Petraglia, 1998, p.88)

${ }^{15}$ http://www.cvu.strath.ac.uk/
} 
assessment. The aim of the questionnaire was, firstly, to assess the success of the project in terms of student motivation and perception of skills and knowledge acquired; and secondly, to provide feedback for future development. Throughout the period of the project the groups were also observed informally in the computer laboratories.

The project has run successfully on three occasions. The feedback presented here covers the academic sessions 1996-97 and 1997-98. Overall, feedback for both years was very positive.

Students were asked if they would like to see the project extended to involve further stages in the procedure (Figure 3 ). In both years approximately $60 \%$ of the respondents favoured an extension of the project.

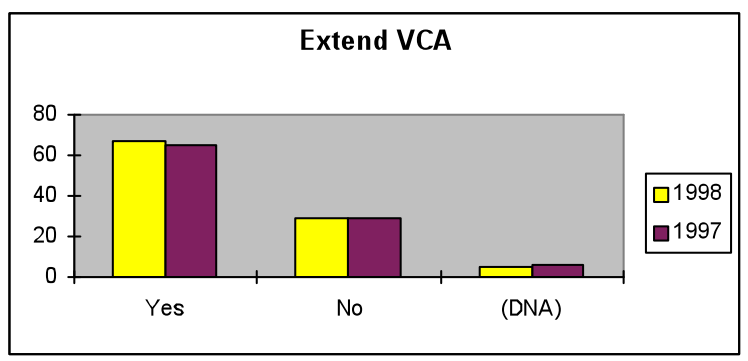

Figure 3

An aim of the Virtual Court Action was to make efficient use of staff time, and indeed for the first two years, class contact time was reduced by one hour each week, although students were unaware of this. The project was never intended to be a substitute for lectures and seminars but was to be used in conjunction with tradition teaching methods. We asked students questions concerning the balance of the project work with lectures and seminars. An interesting result from this was that students were unwilling to reduce or replace lectures and seminars (Figures 4 and 5). This may possibly be a reflection of students' reluctance to relinquish traditional forms of learning and teaching, particularly in first year.

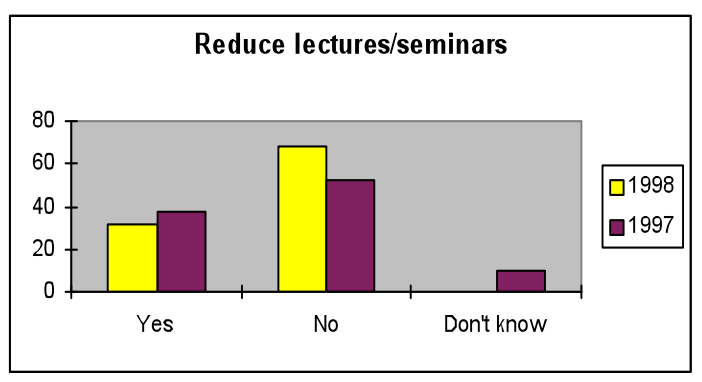

Figure 4

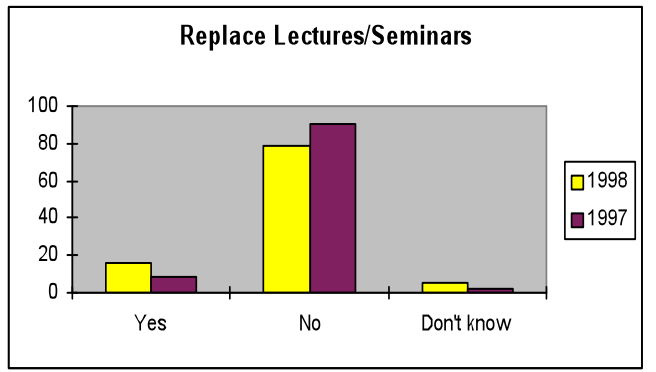

Figure 5 
Confidence levels in both knowledge of court procedure and drafting court documents had increased and although this cannot be equated with competence, it can be regarded as an indicator of how an individual expects to perform in a given situation (Figures 6 and 7).

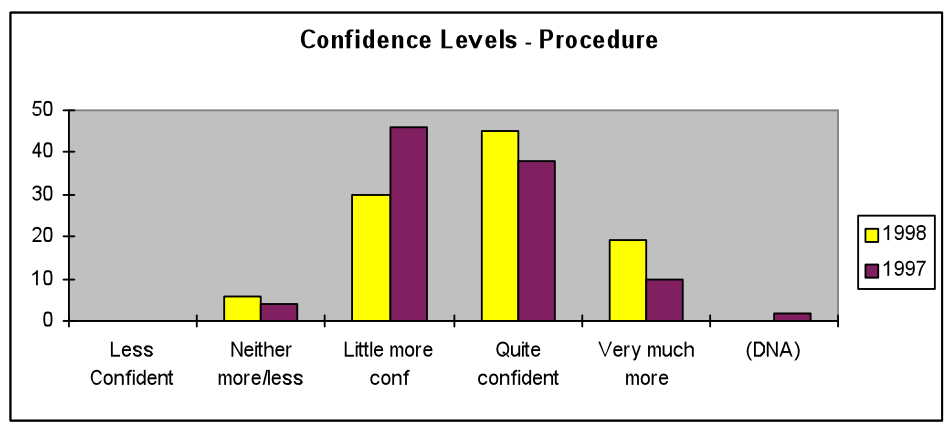

Figure 6

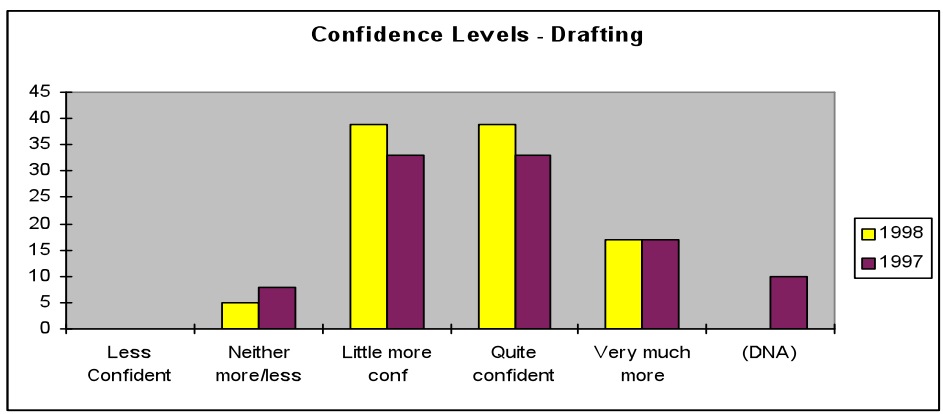

Figure 7

Student comments contained in both the questionnaires and the summative report were, in some ways, more revealing. In particular, they reflected the vocational nature of the project and its perceived relevance to the workplace, resulting in improved student motivation. Some comments revealed how students perceived learning management issues that arose in the project. For example, students observed that:

'The VCA is also achieved without the supervision of staff, therefore focuses the responsibility on the group members. This encourages different learning techniques and different paces of work'

'Responsibility was shared and it was a lot better than other coursework I have done at university. I feel I gained more in depth knowledge form compiling the documents and even more from the Virtual café'

'Having to respond within set timescales .... required that appropriate time management skills were developed, again this is more relevant to what happens in the workplace when targets have to be met.'

The introduction of co-operative learning through the HyperNews discussion group provided students with a forum for peer assisted learning in which they participated 
willingly and which contributed to the effective management of the project:

'Using the legal terminology in the project instead of hearing it in lectures and seminars as well as in conversations with my peers helped me to gain a better understanding more quickly.'

'It also opened a whole new way of accessing info through the HyperNews, news which people might readily use now that they are familiar with it, rather than being told of its existence and its benefits.'

The Virtual Court Action is still in use at Caledonian. Subsequent student feedback from the project questionnaires has been analysed, and has been equally positive.

\section{Situated Learning}

So far in this paper, we have described in detail an instance of CBL. But this learning intervention did not develop without a theory to guide it. In this section we shall examine one theory which influenced our program, namely situated learning, and the effect it had on the implementation of the program.

One of the key texts for understanding situated learning is an article published in the Educational Researcher by Brown, Collins and Duguid. ${ }^{16}$ For them, "learning and cognition ... are fundamentally situated', by which they mean that concepts, like language, are embedded in cultural activities: '[a]ctivity concept and culture are interdependent' (pp.33; 33). Learning is bound to these activities. Citing Clifford Geertz, they point out that 'communities of practitioners ... are bound by intricate, socially constructed webs of belief, which are essential to understanding what they do' (p.33). ${ }^{17}$ By contrast, they argue, much school activity stands apart from the 'coherent, meaningful and purposeful activities' (p.34) which are the mark of a culture's authentic activities. School activities take place within the culture of schools, are not the activities of professionals, and are thus hybrid. Framed by the context of lectures, tutorials, prescribed texts, formal written examinations, semesters, curricula and the rest of school culture, students are deliberately socialised to process knowledge at one remove to the extraordinarily rich context within which practitioners encounter task-based or transactional learning. ${ }^{18}$ Situated learning theorists eschew this approach. For them, authentic learning arises from the experience of being in the situation.

\footnotetext{
${ }^{16}$ Brown, J.S., Collins, A. and Duguid, P. (1989) 'Situated Cognition and the Culture of Learning', Educational Researcher, 18, 1, 32-42 Page references to this article are included in the body of our text above.

${ }^{17}$ Geertz, C. (1983), Local Knowledge, Basic Books, New York

${ }^{18}$ For a description of transactional-based learning in law see Nathanson, S. (1987) 'Putting Skills and Transactions Together in Professional Legal Education' Journal of Professional Legal Education, 187; Nathanson, S. \& Fine, S. (1999) 'The Bar Vocational Course at the College of Law: A Study in Curriculum Coherence', The Law Teacher, 33, 2, 172-195
} 
This point is fundamental to almost all variants of situated learning. ${ }^{19}$ Brown et al cite an example from Lave, that of the dieter in a Weight Watcher class, trying to work out how to determine the exact amount of cheese he was allowed to eat according to the formula 'three quarters of two-thirds of a cup'. ${ }^{20}$ The dieter filled a measuring cup two-thirds full, emptied this on to a cutting board, marked a cross on it, and removed one quarter. Brown et al quote Lave:

'Thus, "take three-quarters of two-thirds of a cup of cottage cheese" was not just the problem statement but also the solution to the problem and the procedure for solving it. The setting was part of the calculating process and the solution was simply the problem statement, enacted with the setting. At no time did the Weight Watcher check his procedure against a paper and pencil algorithm, which would have produced $3 / 4$ cup $\times 2 / 3$ cup $=1 / 2$ cup. Instead, the coincidence of the problem, setting, and enactment was the means by which checking took place' (p.35)

We have cited this example not only because it is a useful example of situated learning, but because it illustrates both the strengths and weaknesses of the theory. The dieter has little information and a set of tools -- a cutting board, spatula and measuring cup -- and with these tools he solves his problem. Lave's description of the learning moment is revealing: "'Then after a pause he suddenly announced that he had 'got it!' From then on he appeared certain he was correct, even before carrying out the procedure"' (p.35) Brown et al describe this solution as activity-based (ie inseparable from the use of the 'cooking-kitchen utensils-dieting' context). The context, in other words, provides tools for learning and problem-solving. There is thus mediation between cognition, intention and situation -- in other words, distributed cognition. ${ }^{21}$

Lave and Wenger have since gone on to develop a sophisticated model of how such learning develops in their theory of peripheral legitimate participation. ${ }^{22}$ Nevertheless, Lave's narrative of the dieter's learning above is silent on a crucial issue: it tells us little about how the dieter came to realise he could manipulate his context so as to achieved the result he wanted. Nor, in spite of the case that Brown et al make for generalising the procedure, has it wholly been accepted that situated learning does facilitate transfer of learning from particular to general. Brown et al do caution that discourse in learning cannot always be 'direct and declarative' (p.40), and go on to suggest ways in which learning can be enabled as part of the distributed knowledge and elaborate support of the

\footnotetext{
${ }^{19}$ The same might also be said of constructivism. For a useful discussion of this, see Confrey, J. (1995), 'How compatible are radical constructivism, sociocultural approaches, and social constructivism?' in Steffe, L., \& Gale, J. (eds) Constructivism in Education, Lawrence Erlbaum Associates, Mahwah, NJ

${ }^{20}$ Lave, J. (1988), Cognition in Practice, Cambridge University Press, New York

${ }^{21}$ Our use of the term 'distributed cognition' derives from Cole, M \& Engeström, Y. (1993), 'A culturalhistorical approach to distributed cognition' in G. Salomon (ed), Distributed Cognitions: Psychological and Educational Considerations, Cambridge University Press, Cambridge. For an interesting discussion of situated learning and distributed cognition, see Nardi, B. (1996), 'Studying context: A comparison of activity theory, situated action models, and distributed cognition' in Nardi, B. (ed) Context and Consciousness, MIT Press, Cambridge MA

${ }^{22}$ Lave, J. \& Wenger, E (1991), Situated Learning: Legitimate Peripheral Participation, Cambridge University Press, Cambridge
} 
social matrix' (p.40). These include cognitive apprenticeships, collective problemsolving, confronting ineffective strategies and misconceptions, and providing collaborative work skills (p.40). Brown et al posit a move from embedded activity to generality in a series of moves from apprenticeship/coaching through collaboration/multiple practice to reflection/articulation (p.40); but again, it is unclear from their model how transfer of learning occurs from one stage to the next. That this does occur in apprenticeship models of education is clear from Lave and Wenger's research alone. Whether this model can or should represent the totality of knowledge processing in a university, though, is debatable.

Most if not all of these approaches challenge accepted classroom practice and theory at a fundamental level, and require substantial evidence if they are to support their claims. This may be one pressing reason why Brown et al finish their article by calling for an 'epistemology of situated cognition' (p.40), one which in particular will help to solve the problem of determining what should be made explicit within the teaching process, and what should be left implicit and understated or absent.

From the point of view of learning management, it is interesting that they highlight this as one of the 'particularly difficult challenges for research', for in many respects this is, as we shall see below, precisely the problem confronting the profile of learning management within the domain of educational theory. It is perhaps to be expected that a theory such as situated learning, which emphasises the importance of creating learning situations, ought to take learning management more seriously than other theories; but there are other reasons why this should be the case. Much of learning management is taken as implicit in traditional pedagogy. It is raised to more explicit levels in situated and constructivist learning. There, the contrast of the explicit and implicit in teaching is another, more phenomenological, version of bringing into the light what has previously remained in shadow. Similar initiatives are present in other disciplines: the figure/ground percept in cognitive studies; in literary theory, reader-response theory and models of the implied reader, and in education the experiential learning of Dewey and Montessori. ${ }^{23}$ It is significant that Brown et al refer to what should be made explicit/implicit in teaching. It is one of the insights of situated learning that it does not treat instructional design as separate from the learning moment, but starts with the student-centred situated activity of learning itself. Indeed, it goes so far as to prioritise activity and perception as 'epistemologically prior -- at a non-conceptual level -- to conceptualisation'. We would not go this far, but as we shall see below, there are valuable lessons to be learned from situated cognition about the relationship that exists in teaching between 'explicit

\footnotetext{
${ }^{23}$ See for example Iser, W. (1984) The Implied Reader, Johns Hopkins University Press, Baltimore. Entwistle and Marton, in their phenomenographic research on what constitutes a 'knowledge object' for students, quote Donaldson:

'We may know in a variety of ways characterised by differing degrees of awareness. Some kinds of knowledge are in the light of full awareness. Others are in the shadows, on the edge of the bright circle. Knowledge on the fringe of consciousness ... is always ready to move to the centre. It is accessible to us, even if we don't attend to it.'

Entwistle, A.C. and Marton, F. (1994) 'Knowledge objects: understandings constituted through intensive academic study', British Journal of Educational Psychology 64, 161-178, p.175, quoting M. Donaldson, Human Minds: An Exploration, London: Allen Lane, Penguin Press, 1992.
} 
knowledge and implicit understanding' (Brown et al, p.41, our emphases)

Since Brown's paper in 1989 there have been a number of challenges to situated cognitive theory, some of them more convincing than others. Some commentators flatly reject its educational grounds. ${ }^{24}$ Other such as Anderson, Reder and Simon argue -mistakenly, in our view -- that proponents of situated learning and constructivism seek deliberately to subvert the intellectual structures of learning in the academy. ${ }^{25}$ More persuasive and subtle is the approach of Joseph Petraglia who, while sympathetic to many of the aims of the constructivist programme, argues that the literature of educational technology has 'finessed the contradictions' in the problem of authenticity which underlie both situated cognition and constructivism. ${ }^{26}$ For him, there is a clear parallel between the problems which IT designers face when they try to construct an authentic learning environment and 'the basic dilemma every constructivist educator faces when importing epistemologically destabilizing notions into what remains a fairly conservative conception of education'. ${ }^{27}$ His answer is to reframe constructivism as a rhetorical activity which is grounded in contemporary rhetorics, and especially the approach known as 'knowledge negotiation'. ${ }^{28}$ For Petraglia this also entails knowledge negotiation between learner and teacher. It is the basis of the educational software being developed by himself and others at Georgia Tech, entitled RealityCheck: A Rhetorical Approach to Constructivist Learning. ${ }^{29}$ This software helps students to negotiate the meaning of written assignments between themselves and their teachers. It is an excellent example of software which deals with learning management issues -- here, the gap between students' constructions of a learning task, and a teacher's interpretation of the same task. To adopt the terms of Brown et al, Petraglia makes explicit what often remains damagingly implicit in the learning task.

By contrast, Diana Laurillard argues vigorously against some of the fundamental situationist positions which Brown et al describe above. According to her, learning in educational contexts 'requires learning about descriptions of the world, about a particular way of looking at the world'. ${ }^{30}$ While situated learning can be attractive in certain contexts, she is sceptical of its broader claims and especially of its epistemology. She cites Lave's example of the dieter, and then places it within a different context:

Suppose the weight-watcher were trying to work out his share of a discounted car hire with a couple of friends and had to figure out the logically equivalent problem of one-third of 5 per cent off the total cost? The unity between problem, context and solution is not quite so apparent here. The point of an academic education is that knowledge has to be abstracted, and represented

\footnotetext{
${ }^{24}$ See for example Phillips, D.C. (1995), 'The good the bad and the ugly: The many faces of constructivism', Educational Researcher, 24, 7, 5-12

${ }^{25}$ Anderson, J.R., Reder, L.M., \& Simon, H.A. (1996), 'Situated learning and education', Educational Researcher, 53, 4, 5-11

${ }^{26}$ Petraglia, J. (1998), Reality by Design: The Rhetoric and Technology of Authenticity in Education, Lawrence Erlbaum Associates, Mahwah, NJ, p.12

27 Ibid.

28 Ibid

${ }^{29} \mathrm{See}$ http://www.lcc.gatech.edu/gallery/realitycheck/

${ }^{30}$ Laurillard, op.cit, p.22
} 
formally, in order to become generalisable and therefore more generally useful. It then empowers people like the weight-watcher to deal with quantities of things other than cottage cheese. ${ }^{31}$

For Laurillard, academic knowledge has the character of a 'second-order' discourse, heavily reliant on symbolic representations, and a type of reflection on the world. ${ }^{32}$ Citing Vygotsky (who is also claimed by radical constructivists) she calls it 'mediated learning', and thus separates it from situated learning. Drawing upon phenomenographic research findings and methodology, and other sources such as Pask's conversation theory, Laurillard drew up a sophisticated and highly generalisable 12-stage 'conversational' framework which identified the activities necessary for the learning process to take place. ${ }^{33}$ This framework articulates in more persuasive detail than the model of Brown et al quoted above how transfer of learning is effected from one stage to the next.

In her commentary on the framework Laurillard does state that her model is not applicable to versions of 'learning through experience'. Indeed, even while she argues a convincing case against the more ambitious claims of the radical situationist programme, she does acknowledge the appropriateness of such forms of learning within the academy. Nevertheless her analysis of the differences between situated cognition and more traditional forms of university teaching and learning is acute, and is paralleled by the work of others. Resnick for example established four distinguishing features of academic learning which separated it from everyday learning, three of which are given also by Laurillard, namely that academic learning relies on abstraction, on the manipulation of symbolic representations, and aims to create highly generalisable learning. ${ }^{34}$ Laurillard's model, though, is the more encompassing. Chapter 12 of her book attempts to apply its methodology to the academic environment within which educational technology is used and implemented. At first glance, it would appear that learning management has come of age. The chapter gives a blueprint of roles and responsibilities within the organisational infrastructure of a university which includes both the design and developmental phase and the implementation phase. However this is very much a list of what ought to be, rather than an analysis of actual learning management, or a methodology by which learning management might be theorised. It tells us how we might prevent implementation and management going wrong, but tells us little about how it has gone wrong in the past, and gives little theoretical grounding. Interestingly enough, while she deals in great detail with issues raised by Brown et al of 'explicit knowledge and implicit understanding' in the design and development stage, she does not deal with them at the stage of learning management.

From this brief overview of the issues raised by situated learning and constructivism it is clear that the theoretical ground is still a controversial one. For our aims in a civil and

\footnotetext{
${ }^{31} \mathrm{Ibid}$.

${ }^{32}$ Ibid., p. 27

${ }^{33}$ Ibid., p. 103

${ }^{34}$ Resnick, L. (1990) 'Instruction and the Cultivation of Thinking', in N.J. Entwistle, ed., Handbook of Educational Ideas and Practices London, Routledge, pp.694-707
} 
criminal procedure module, namely to provide students with an environment in which to learn procedural law by discovery learning, we were faced with the problem of interfacing situated learning with lectures, tutorials and assessments. In the end, we needed to take the Laurillard approach and integrate the theoretical application of Brown et al. Just how we did so was in the way we managed learning in module.

\section{Learning Management}

Draper defined learning management, you will remember, as 'control or management or administration' of activities that allow learning to take place. The use of computer labs in the teaching and learning in the Virtual Court Action was one such issue. At first glance there could scarcely be anything simpler. But when we consider the assumptions and the decisions which lie behind the simple administrative action of booking a lab then it becomes clear how complex are the issues involved. Educational concerns surround apparently quotidian issues such as centralisation of room bookings, the types of labs available to teach in, the layout of computers in the lab; software loading and access, and the like. Often, traditional frames of educational delivery are embedded in the way we use the labs. ${ }^{35}$

With regard to the Virtual Court Action there were a number of educational decisions which had to be made before the room was booked. Should the lab be booked at all for a class? ${ }^{36}$ Would it be educationally more productive if students were introduced to the software and allowed to proceed with it at their own pace? How would the computerbased learning be embedded with and linked up to other activities in the module, and what effect would that have on the rest of the module syllabus?

For us, it was important that students were given instruction in email and HotDocs document assembly, and had handbooks that described the key functions they would use in the software. Flexible drop-in time was also crucial for students. However, Faculty policy regarding the labs prioritised class time over drop-in time: whenever a class was being held in a lab, those students using it for drop-in purposes had to move to another lab. There was thus tension between class time, and students' drop-in time. From being directed learning carried out at a student's own pace, learning requires to be completed within a set period of time, thus contradicting the notion of self-paced learning which is one of the oft-quoted advantages of CBL.

\footnotetext{
${ }^{35}$ We use the term 'frame' here, and later in our conclusion, in a way similar to Minsky's concept. The frame is the structure through which we come to make sense of social situations and concepts of reality. A 'library' frame, for example, would consist of many different ideas: shelves, books, periodicals, catalogues, reading tables, tickets, borrowing rights, and so on. Schank \& Abelson elaborate the frame concept by developing the dynamic model of the 'schema', in which the ideas are attached to the frame, and constructed and used whenever we enter the frame -- borrowing a book as one category of reader instead of another, consulting reference books, paying fines (Schank, R.C. \& Abelson, R.P. (1977) Scripts, Plans, Goals and Understanding, Hillsdale, NJ: Lawrence Erlbaum Associates)

${ }^{36}$ In a recent ITFORUM discussion some members debated the advantages of centralising computer use in a computer lab, as opposed to dispersing computers throughout classrooms. See archived messages, 26-29 June, 1999 at http://itech1.coe.uga.edu/itforum/home.html
} 
These and many more learning management issues are replete with questions of educational philosophy, approaches to learning, deeply embedded concepts of what constitute appropriate forms of teaching and learning, and the like. They are important issues not only for the smooth administrative running of the class, but also for the way in which CBL is used by students. They involve awareness of the context of learning, not only from a staff but also from a student perspective. It is for this reason that Draper contextualises the management of $\mathrm{CBL}$, seeing its introduction as happening within social contexts of what went before, and affecting both learners' and teachers' expectations of what the CBL might achieve. The change in the environment of learning that CBL brings about clearly needs managing; but what Draper points out is that change in the environment

exposes with a new clarity issues that have really always been there. When someone naïvely replaces a human activity by a machine one, then we see by the way it breaks down some of the less obvious things that were in fact being done by the human. This has proved true in office automation, and I have seen it in education.

Draper's metaphor of uncovering or stripping away is appropriate to the development of the Virtual Court Action. It was only by attending to the learning management issues underlying the pre-existing traditional frames of learning that we were able to avoid naïve replacement of human with machine activity. For example, the use of help text in dialogues gave information to students to enable them to make the right decision in the choices confronting them in the dialogues. Again, discussion forums helped localise and encourage engagement with the practical use of legal concepts, and encouraged students to think about more unusual procedural situations.

Issues such as these reveal that perhaps the fundamental point about learning management is that it is often unregarded in learning theories. Draper points out, for instance, that it is absent from Laurillard's model of mathemagenic activities. ${ }^{37}$ Whether or not learning management can be separated from theory an issue we shall consider below. But the general point about its relatively low profile in C\&IT learning theory is interesting in itself. How could this have come about?

The answer to this question has three parts. The first has to do with the difficulty of examining learning management in classroom practice. With its many and synchronous events, learning in schools, further and higher education is an object of remarkable, multi-layered and everchanging complexity. Moreover, a class is always a class in time, and its precise features can never be replicated experimentally. ${ }^{38}$ Secondly, CBL is still a new form of learning and teaching, and teachers need to routinise its use before they feel comfortable in using it. Routinisation plays an important role in all skilled activity, in teaching as much as in any other profession, and allows teachers simultaneously to manipulate knowledge, be aware of and responsive to, student engagement, and adapt teaching plans to suit class conditions. All of this is the result of considerable mental

\footnotetext{
${ }^{37}$ Laurillard, op.cit.

${ }^{38}$ Landauer, T.K. (1995) The Trouble with Computers: Usefulness, Usability and Productivity, MIT Press, Cambridge, MA.)
} 
processing: it has been estimated that a primary teacher in the course of teaching in a typical day might make as many as a thousand decisions about such matters. ${ }^{39}$ In higher education, teaching in tutorials involves quick decision-making on the part of the tutor: which sub-topic to elaborate, how to alter the pace of a tutorial or fine-tune an activity, how to create atmosphere and mood, or emphasise important points, how to stimulate student discussion, when to ask a question, the sort of question to ask that will help students best in a given situation, and so on. Teachers' early manipulation of these learning management matters gradually becomes more automatic as their experience accumulates, and as they learn from colleagues and students. Indeed the process of automatising aspects of teaching is essential for improvement: teachers move much of the process of conducting tutorials into tacit knowledge, so as to avoid overload when dealing with discipline knowledge and students. The introduction of CBL into a class has the potential to disrupt this well-tempered routine at a fairly deep level: if a tutorial is held in a lab, for instance, then the 'tutorial frame' for both staff and students is significantly altered.

The third part of the answer lies in the nature of the decisions to be taken at design and implementation stages, and in the distinction between CBL designer and CBL implementer. It is axiomatic that CBL is designed for an audience, but that audience includes not just students who will use the program as a learning resource, but staff who will use it as a teaching resource. Definition of audience needs, prior knowledge, and the like, and the operationalisation of this in a CBL program are difficult and complex matters. Unless these matters are made overt, their implications for classroom practice may not become apparent to those teachers who will be implementing the CBL. For them, the decisions that are made at the stage of implementation are almost wholly linked to classroom practice and are practice-based. Their learning management is thus based on practical reasoning, a form of Aristotelian phronesis, in which they integrate knowledge of students, subject expertise and local knowledge of university conditions and procedures. We can learn something more of this situation if we apply to ourselves the analytical tools of one version of phronesis, namely Donald Schön's theory of reflection.

\section{Schön and Learning Management}

If we try to locate the idea of learning management in Schön's landscape of practical reasoning, it soon becomes apparent that the term does not belong to the high ground of theory and theoretical analysis, but to the swamp of everyday classes and quotidian interaction of students, staff, and others. It is an environment which cannot be precisely controlled, (and hence is less amenable to experiment and quantitative analysis), and in which it is difficult to discern all the factors which converge on learning events. As Schön has it,

$[\mathrm{t}]$ he problems of real world practice do not present themselves to practitioners as well-formed structures. Indeed, they tend not to present themselves as problems at all but as messy, indeterminate situations. ${ }^{40}$

\footnotetext{
${ }^{39}$ Jackson, P.W. (1968) Life in Classrooms, Holt, Rinehart and Winston, New York

40 Schön, Donald (1987), Educating the Reflective Practitioner, Jossey-Bass, San Francisco, p.4
} 
For many reasons, implementing CBL is often such a messy situation, and in order to 'solve' the problem teachers require to integrate local knowledge of place, timetables, module content, curriculum and the like with subject expertise, experience of range of ability and knowledge in a class. But the word solve is in inverted commas because in a sense that is precisely what teachers can never do. In talking about problems and solutions we are, almost by default, using the language of theory to describe a situation where teachers do not solve problems but create the conditions for learning in a situation that is always messy, frequently indeterminate, endlessly changing. Each year there are new classes, hardware, software operating systems and CBL upgrades; module structures and timetables are changed as teaching and learning and assessment regimes are altered, and so on.

Schön's response to what he called the dominant 'technical-rationality' approach of higher education towards knowledge processing was to focus on the concept of 'knowing in action' -- a form of fluent integration of skill and knowledge in performance of a task. ${ }^{41}$ The development of knowing in action for Schön was the result of two types of reflection: reflection in action, in which the knower would respond to variations of the messy situation as it unfolded, and reflection on action, in which there would be reflection post factum. Of the two forms of reflection, Schön values the former over the latter, mainly because it is easier to rationalise after the fact and thereby mistake or disguise the real nature of aspects of the problem which only occur in the heat of action. For Schön, this can come about when our 'espoused theories' -- the theory we hold whose tenets we think we act by -- conflict with our 'theories in use', with the result that 'distancing' takes place: that is to say, we attribute the failure in our actions to another, external cause and not the conflict between our espoused theories and theories in use. ${ }^{42}$

Schön's analyses of reflection and knowing, aptly describe the gap that can open up between CBL design and implementation. As we pointed out above, every planned learning interaction has some theory of learning and action behind it, even if the theory is unarticulated. The same holds true for CBL, which by its nature requires to be a carefully planned learning environment. However, if the theory behind the program is at odds with the way in which the program is implemented, then the result as far as students' learning is concerned may well be unsatisfactory, and 'distancing' brought into play in order to explain the failure of the program. The failure may lie elsewhere though: in the gap between what the program espoused in the way of learning theory and objectives, and what it was used for in the implementation, for example; or it may lie in procedural and tacit knowledge that the program assumed the students or staff had, and the forms of knowledge they actually possessed in practice. If we replace 'espoused theories' with CBL design, and 'theories in use' with CBL implementation, it becomes easier to see why the relationship between CBL design and learning management is a difficult one. Our espoused theories are generally given much more attention than our theories in use because they are easier to perceive and discuss. Situated learning as a large and growing literature, and it can be a valuable tool in the design of CBL. But when we operationalise it, we inevitably turn it into a theory-in-use.

${ }^{41}$ Schön, Donald (1983), The Reflective Practitioner, Avebury, Aldershot, p.49

${ }^{42}$ Educating the Reflective Practitioner, pp.260-64 
Both theories-in-use and learning management are more protean and difficult to plan in prospect, and to discern clearly in retrospect. CBL design and its objectives may be stated with admirable clarity, but if these are to be achieved then we need to reflect on how our learning management strategies and theories fit or conflict with the objectives. For staff, this involves a form of 'knowing in action': an awareness of the interface between our own teaching and learning routines and the theories underlying them, and a knowledge of the practical and theoretical possibilities in the CBL we want to use. For example, the distinction we made in the Virtual Court Action between what were, from the students' point of view, cognitively simple or complex tasks was critical to the success. Thus in the drafting of an initial writ, the concept of jurisdiction was usually a difficult one for students to grasp, and this concept had to be 'scaffolded' in the project by means of dialogue and help text in the way we have described above. However, situated learning is a form of learning by discovery. Was there therefore a discrepancy between our espoused aim to enable students to learn by discovery, and our theory-inaction, guided learning? And would this not be confusing for students? Potentially, this always existed. But we would argue, with Laurillard, that any discovery learning approach must be planned to co-exist with other, more traditional frames of teaching and learning in higher education.

The dialogue help texts and the discussion forums provide a good illustration of this in practice. When we scripted the program it became clear that problems would occur if the program was implemented without proper attention to learning management issues and if those issues were not clearly addressed throughout the whole of the learning experience. In developing a situated learning environment, particularly a computer-based environment, we were changing quite radically what students expected or had become used to as their traditional organisational and support structures. If students miss a point in a lecture, they can ask the lecturer for clarification either during or after the class. If the learning environment changes to alter the method of delivery of that information, the student has to know the new procedure for obtaining the same type of clarification. Providing merely a learning mechanism (computerised initial writ) without all of the necessary learning management support (training, availability, locations, where to get help, assessment requirements, definitions of terms, help with tasks, etc.) will often result in a poor learning experience for the student and create severe organisational difficulties for staff. With this knowledge, we set out to design a project which would be both educationally relevant and well-managed, and where the principles of situated learning were carried through in the management of student learning.

Schön's reworking of practical reasoning is only one version of it. ${ }^{43}$ The theory and tools of action research could be used in a similar way. As an example of phronesis, however,

\footnotetext{
${ }^{43}$ Critics in education and in other disciplines have pointed out the weaknesses in Schön's account of professional expertise. In particular he overemphasises craft and artistry at the expense of routinisation, and little attention is paid to co-operative learning (See for instance Barnett, R. (1992) Improving Higher Education, Open University Press, Milton Keynes; Barnett, R (1994) The Limits of Competence, Open University Press, Milton Keynes; 1994, Jones, P. (1996) 'We're all reflective practitioners now: reflections on professional education' in Webb, J., \& Maughan, C., Teaching Lawyers' Skills, Butterworths, London).
} 
it serves to show how such reasoning can be applied to the project of theorising learning management.

\section{Conclusion}

As we have seen in our case study, learning management was crucial to the success of the project. Situated learning theory guided us on many aspects of design, particularly in the early stages. We were thus able to identify what, in the words of Brown et al, 'should be made explicit in teaching and what should be left implicit'. But in order to imagine this in detail, we also had to imagine, from a student's point of view, the experience of using the program, and try to imagine what the learning management issues uppermost in the student's mind might be. ${ }^{44}$

Throughout this paper we have argued that learning management is a hitherto relatively unregarded aspect of educational technology, one which is nevertheless crucial to the learning events which are to take place. For these reasons we have argued that it may be possible to articulate aspects of learning management theorising in versions of practical reasoning or phronesis, taking as our example Schön's structures of reflective thought. Above all, we have argued that the design stage of CBL should, as far as possible, take into account the learning management issues which will be faced by those implementing the technology. Classrooms, after all, and the learning events which take place within them, are the intersections of many overlapping, sometimes contradictory discourses and situations. This heteroglossia, to borrow a term from Bakhtin, is inevitable: what we need to do as designers as well as teachers is to manage the learning experience so as to help students negotiate the contradictions and improve their legal learning. ${ }^{45}$ Central to this is the expression, as Draper has it, of 'our practical know-how in our theories' ${ }^{46}$ The Virtual Court Action succeeded, in our view, because the planned convergence of professional practice (what lawyers do when preparing for a court action) and academic practice (the structure of learning aims, the constructivist forms of situated learning, the merging of learning and assessment) in our opinion could only have been achieved because learning management issues were taken into account at the design stage as well as the implementation stage.

\footnotetext{
${ }^{44}$ This approach has been developed in much greater depth by Prosser and Trigwell who argue, from a phenomenographical point of view, that the quality of student learning can be improved if staff work to determine how students perceive their learning environments (Prosser, M., and Trigwell, K. (1998) Understanding Learning and Teaching: The Experience in Higher Education, Open University Press, Milton Keynes)

${ }^{45}$ Bakhtin, M. (1981) The Dialogic Imagination: Four Essays, Holquist, M. (ed), University of Texas Press, Austin, Texas

${ }^{46}$ Draper, op.cit.
} 